\title{
Understanding of Socially Vulnerable Individuals on Oral Health and Access to Dentist: A Brazilian Study
}

\author{
Cristina Berger Fadel1*, Jean Érick Langoski1', Marina Izabela Machado1, \\ Juliana Maria Stremel1, Danielle Bordin², João Alfredo Madalozo 3 \\ ${ }^{1}$ Departament of Dentistry, State University of Ponta Grossa, Ponta Grossa, Brazil \\ ${ }^{2}$ Paulist State University, Araçatuba, Brazil \\ ${ }^{3}$ Departament of Geography, State University of Ponta Grossa, Ponta Grossa, Brazil \\ Email: ${ }^{*}$ cbfadel@gmail.com, je-erick@hotmail.com, marina iza@hotmail.com, jujumaria 7@hotmail.com, \\ daniellebordin@hotmail.com, jamadalozo@onda.com.br
}

Received 16 September 2014; revised 23 October 2014; accepted 19 November 2014

Copyright (C) 2014 by authors and Scientific Research Publishing Inc.

This work is licensed under the Creative Commons Attribution International License (CC BY). http://creativecommons.org/licenses/by/4.0/

(c) (i) Open Access

\begin{abstract}
Social vulnerability experienced by collectors of recyclable materials has a strong influence on their understanding and confrontations health. This research aimed to explore the relationship between oral health and perception of subjects in a context of social disadvantage, in order to support concrete alternatives for action on (oral) health conference. This was a qualitative study carried out with representatives of an autonomous community of Brazilian collectors of recyclable materials. Data were collected through interviews and focus group treated with the technique of qualitative analysis. Respondents showed perceptions of etiology and care practices on oral health promoted beliefs and values collectively instituted in a social risk territory. Also, they associate the quality of their oral health and their difficulty of public access to the context of social vulnerability. This study suggests the adoption of protective, educational and interceptive in oral health practice in order to improve and enable the oral health status of this population.
\end{abstract}

\section{Keywords}

Health Care, Vulnerable Populations, Oral Health

\section{Introduction}

The recyclable materials accumulation, added to the unemployment, informality and precariousness of labor re-

"Corresponding author.

How to cite this paper: Fadel, C.B., Langoski, J.É., Machado, M.I., Stremel, J.M., Bordin, D. and Madalozo, J.A. (2014) Understanding of Socially Vulnerable Individuals on Oral Health and Access to Dentist: A Brazilian Study. Open Journal of Preventive Medicine, 4, 868-875. http://dx.doi.org/10.4236/ojpm.2014.411098 
lations, low access to information, services and the limited availability of resources [1] has represented one of the sources of income for many Brazilians, who are in the collection of recyclable materials an important source of livelihood and a possibility of inclusion in the social world and work [2].

Studies show the poor living conditions, work and structural factors of this group of workers as important potentiating agents of human vulnerability [1]. These weaknesses exposed by individuals and communities are understood as part of a social process, in that it incorporates inherent to the individual and collective practices and present intertwined attitudes, values, beliefs, feelings and standards. Thus, they become able to greatly influence human understanding about a particular object.

Particularly to the field of public health, it is assumed that exposure to adverse situations is distributed unevenly individuals according regions and social groups [3] [4] and also is strongly influenced by social determinants of healing and human sick. Thus, aware that adverse socioeconomic peculiarities experienced by collectors of recyclable materials have a strong influence on their understanding and their confrontations health, this study exposes the relevance of accessing the perception of these subjects.

Based on these, and also the lack of studies in the literature that consider the perceptions of collectors of recyclable materials, it was sought in this study to explore the relationship between oral health and perception of subjects in a context of social risk, in order to support alternative concrete intervention in health (oral) conference.

\section{Methodology}

\subsection{Design, Setting and Sample}

This cross-sectional observational study, exploratory and qualitative approach was performed on an autonomous community of recyclable materials in a city of southern of Brazil, in 2013. The sample was chosen through the unique status of weakness exposed by the subjects, taking into account its historicity and its responsiveness around the vulnerabilities related to the theme and its aftermath.

The study was formed by 31 families and approximately 180 individuals living in an area of invasion, considered in social risk, this society is marked by highly social and economic precarious indicators, such as lack of water supply and sewage, unregulated electricity, plenty of garbage, risks of various kinds, among others. In the list of your daily, adults and children assignments are meant to collect, select and sell solid recyclable materials such as paper, cardboard and glass, as well as ferrous and non-ferrous materials and other reusable materials.

The study population was formed by the totality of informal representatives, but declared legitimate and popularly of that community $(n=6)$, all women with incomplete primary education aged by 26 to 57 years. The number of subjects was defined initially considering the possibility of recruiting other reporters. However, during the study, the amount proved to be sufficient, since the empirical data obtained allowed to draw a comprehensive picture of the issue under investigation. Although the qualitative methodology work with a small sample of subjects, authors have shown that in one speech is contained the whole representation of certain groups in historical, socioeconomic and cultural specific conditions enabling a trustworthy manner deepen the complexity of the phenomenon under study [5].

\subsection{Data Collection}

The elements of interest for the study were seized by the technique of focus group interviews [6], held within the community concerned and a president elected by own informants home. It was performed an informal discussion guided by a previously prepared script, prepared in order to guide a conversation, aiming to apprehend the point of view of the interviewees on pre-established themes: perceptions and practices of oral health determinants attributed to current health status, the relationship between life history and oral health, the impact of health status on quality of life and social life, barriers related to access to dental care, as well as experiences and expectations regarding dental care. The researcher allowed free speech of respondents while the design of the conversation, trying to keep in tune with the objectives of the research interview.

This step was conducted in a one meeting, by a single researcher who explained about the functioning of the group, voluntariness, confidentiality and non-identification of participants, and requested consent to record. Lasting about 50 minutes, it was used the saturation criterion for closing [7].

At the end of the interview, subjects were instrumented on educational and preventive aspects of oral health through dialogue with researchers and the acquisition of a printed information sheet. 


\subsection{Data Analysis}

The speeches were transcribed and analyzed qualitatively using the technique of qualitative analysis [8], which consists in discovering the meaning clusters that foster social capture of the interviewees about the object of study, as well as the psychosocial context that surrounding this object [9].

In the pre-analysis step, the material was organized into three thematic categories and a superficial reading of the same was held aiming at a comprehensive apprehension of meaning. Subsequently, further exploration of this material was made with thorough reading of the speeches, extracting words or phrases that answered the guiding questions, so-called core meanings in order to subcategorize them [10].

\subsection{Research Ethics}

All subjects were informed about the purpose of the research, their character and willingness of non-identification, as well as how to collect, analyze and target data. Those who agreed to participate did so through the signing of a free and informed consent. The study was approved by the Ethics Committee on Research Involving Humans of the Ponta Grossa State University (COEP-UEPG Opinion No. 226.155/2013), respecting the dictates of Resolution 466/12 of the National Health Council (Brazil), and the Declaration of Helsinki.

\section{Results and Discussion}

The community of recyclable material collectors was composed mostly of young adults with low education and less than one Brazilian minimum wage (US \$308.00) monthly income. The households were composed of married couple and 3 - 4 children, or couples with young children and grandchildren. Residences occupied areas unsuitable, were built of wood and plastic sheeting, composed of two or three rooms. The water access was from contaminated streams and the electricity was irregular.

\subsection{Category 1-Self-Perceived Oral Health}

Self-perceived oral health, interpretation of the experience of health and its condition in the context of daily life [11], it is becoming an interest research object [12]. Understood differently by each individual, society and generation, carries a wide variety of experiences and values [11], which are based on the information and knowledge available in each environment [13]. Exposed as an indicator of multidimensional nature, it relates as well as physical and subjective oral aspects, also with socioeconomic and demographic factors [3] and may reflect previous experiences with dental care, or even expectations for oral health to some group [14]. Also found in the self-assessment variable health its greatest predictor effect, superseding the oral clinical variables [14].

\subsubsection{Oral Health Status}

The precarious living conditions of the collectors in this study revealed an unexpected and insightful influence on their perception of health, noting that oral diseases are not a condition accepted. This result endorses the so-called critical geopolitical populations attribute, which is the understanding that every perception, value and observed practice should be analyzed both in the context of social inequality and space as in power structures [15] [16]. But this result is shown in odds with the perception that oral health for adults and elderlies, which, for the most part, say they are satisfied with their oral health despite the precariousness of their clinical conditions [17]:

"Oh, I think my mouth health is bad. I thought I'm poor and collectors of recyclable materials, my mouth doesn't need to be like this."

“... Mine neither, there are many ugly things. Everyone deserves good tooth, right?”

Although the health assessment by lay people in general, show disparity with the clinical condition found [11] [17], it was observed among respondents, a perception that links the need for clinic dental treatment for oral health condition, though, considering different from those analyzed by the dentist, as social values, beliefs and perceived vulnerabilities:

“There is a tooth here that needs treatment, I know it's just like my husband's. But for us, who are poor and lives with garbage is really complicated have beautiful teeth. I think it really influences, it’s difficult.” 
"(...) When it leaves those hard wounds in my mouth, I know I have to look for the dentist, I leave the service only if have no way, because the money of the day fouls."

“(...) It seems that we're with a brick in our mouth, the tooth gets high... so, we need to go to the dentist. I think it might be messing with such dirty thing... but I never go to the dentist.”

\subsubsection{Influence of Oral Health in Everyday Practices}

Problems associated with oral health have been increasingly recognized as important causes of negative impacts on daily performance and quality of life of individuals and society [3]. The absence of dental elements with significant aesthetic value and strong impact on masticatory function, as well as the experience of pain or oral discomfort are often cited in the literature [3] [18] and it also supports the results of this study.

The collectors of recyclable materials clearly exposed the association between missing teeth, their social status and barriers in everyday life:

-At work:

“I think it (missing teeth) interferes with work, because if you don't have good teeth, you can not get good service (...). But with so many things that we need, where is the money to pay the dentist?”

"That (missing teeth) counts a lot, if you want a fix servisse, you have to take care of your appearance, especially of your teeth. With this work we can't take care (...).”

“... They think if they don't take care of that appearance as well, you can't take care of the office they will give you... else who is poor and lives of garbage has no chance".

"And the worst is that the same thing happens with our children... well, we wanted, but we can't take good care of their teeth... so without good teeth, our children who were created here in the trash can't arrange a better job and end up working for right here, and we didn't want it for them.”

-In communication skills and social contacts:

"When I see a party I close the face, when I felt my teeth were better, I took the pictures, giggled... felt better, despite the poverty. Then I looked in the mirror and saw that wasn't good, I started to take pictures with my mouth closed, people look and say I was with the bad guy, brave face. But what will I do? Hide the teeth."

"We will talk and already give up, huh? We ourselves feel that we have bad breath in the mouth... Also, working with the garbage all day I think the smell gets on us."

-Masticatory function:

"It's hard to eat without the teeth, right? We'll eat anything hard and we can't. And here we eat everything, no luxury."

"We want to eat an apple and we can't because is expensive, but when we purchase, we have to eat kust like a child, shaving with spoon."

The relationship between pain variable or oral discomfort and impact on daily activities was not directly mentioned by the respondents of this survey, despite showing is closely associated with teeth loss and exposure to physical and social risks:

"I took them all (teeth) because my entire pregnancy I suffered with toothache and now I'm out of sheets... most here do it to avoid the risk of suffering pain and the risk of having no way to pay the dentist."

"I also pulled everything (teeth) because toothache makes me want... I don't know what, right? I have no condition to be fixing my tooth and buying expensive thing to wear in the mouth.”

\subsection{Category 2-Elements of Guiding Oral Conditions}

Considering the broad conceptual provisions relating to the health-disease process, which determine which individuals or populations, throughout its existence, will experience health and disease based on their potential, their living conditions and their interaction with them [19], it assumes the mouth state with intricate biological conditions (age, sex, genetic inheritance), the physical environment (geographic, human occupation, nutrition, sanitation, housing) as well as the socioeconomic environment and cultural, which expresses levels of occupation and income, access to formal education and leisure, the degrees of freedom, habits and forms of interpersonal rela- 
tionships, the possibility of access to services aimed at the promotion and restoration of health and the quality of care provided [20] for them. This perception based on etiologic triad: biology, physical territory and social territory was evidenced by the collectors of recyclable materials.

\subsubsection{Propellants Aspects of Illness (Oral)}

With regard to the aspects related to the lack of maintenance of teeth, most respondents believe that they are guided mainly on individual responsibility, self-care, habits adopted lifelong and precariousness of their living conditions. This result corroborates previous studies [21] [22].

“... I think my tooth has spoiled because of coffee and cigarette, because I smoke and drink coffee enough... I learned to smoke early, is common smoking here."

"... My girl has enough spoiled tooth, because she eats a lot of candy and she doesn't brush the tooth properly. I advice to toothbrush, but I don't have enough time to take care if she brushed the tooth or not... and I can't buy a new toothbrush all the time. I work all day long, the end of the day I just want relax.”

Still, for the subjects of the present study and in agreement with findings of other studies [22], another important predictor of oral diseases mentions a past without information and knowledge about oral hygiene habits, without encouragement or motivation, and without access to inputs and a oral health professional.

“(...) But I myself have never gone to the dentist, nobody has encouraged me, my mother didn’t tell let’s goto the dentist daughter, I'll take you there... so, lose everything!"

"I have never heard that mother told us to brush our teeth... there wasn't a toothbrush where we lived... here nobody talks too much about these things, because they know that to take care of the teeth cost a lots of money."

\subsubsection{Facilitating Aspects of the Conquest by (Oral) Health}

Popular culture, the acquired knowledge throughout life and individual or collective beliefs were the factors that mostly permeated the speeches seized in connection with the acquisition and maintenance of oral health. The literature points to similar developments, in particular, at-risk populations with socioeconomic and educational deficit [19] [22].

"About the salt I know that does not spoil, because my grandfather said when he had toothache, go there and make brine and rinse the mouth, it will kill the microbes. It was his way, he knew it would work... he could never go to the dentist and never brushed too, he didn't know how to pick up a brush..."

Another related aspect of the subjects were oral hygiene habits, emphasizing the importance of flossing. The perception of collectors reveals the relationship between poor oral health and financial condition again, emphasizing the difficulty on access to dental supplies.

"I don't have money to pay for a dental floss. I use plastic baggie (...) if there's not floss I use this, at least I'm doing something."

"To clean well, it's necessary to use the toothbrush and to substitute the dental floss, I usually use the stitching yarn."

The replacement of traditional dental cleaning agents, with a view to improving the quality of care, was also found in the literature [23].

\subsection{Category 3-Dental Care}

Oral diseases, mostly don't present any risk to life; however, its evolution, and injury prevalence are important in individual and collective life impacts, and should be considered in the management of public policies [24]. The incidence of dental problems can arouse prejudice in routine activities, such as reduction of hours of sleeping, not performing some leisure activities, food restrictions, psychological disorders related to decreased selfesteem and loss of work days [25], therefore basing the search for the solution of the disorder. Pain, discomfort, functional limitation and social situations that are directly relate to the demand for dental services, which corroborates the inequality in disease patterns and service utilization in populations with higher social risk [26]. 


\subsubsection{Reason for Consultation}

The usage of dental services is persuaded by different and multiple determinants including sociodemographic factors, perceived need, and importance attributed to oral health [26]. The dental origin pain, considered one of the major causes of human suffering and serious problem for public health [24] fosters these very negative psychosocial and socioeconomic repercussions, causing disabilities, impaired quality of life and work absenteeism [25]. This aspect was addressed in speeches, in particular as to the difficulty in performing daily activities:

"I had to go to the dentist, it was a horrible pain! It swelled, I could not leave the house and could not work. Horrible pain, pan! My husband charges me when I don’t go to work, because I help him to pay all the household bills."

"I went to boot, it was sore, with root already appearing. I can't feel pain, because I need to be good to take care of my husband and my kids."

Although the toothache affects people from different social stratum, some researches suggest higher prevalence of pain in individuals with greater individual and social vulnerability [18] [24], with the direct social environment or indirectly related to dental pain [25].

\subsubsection{Access}

The perception of collectors of recyclable materials on access to public dental services endorse the classical interpretation, linking it strongly to the simple presence of the professional in their field of work, the number of professionals, the availability of an appointment, the severity of their oral condition and being treated well by the dentist:

“(...) We arrive (public health service) with pain and still takes luck that has dentist to boot, he/she always finds a way, and treats us well... but there are people who need to score here for three or four months."

"A person will not get pain, public health needs to improve, it’s not the lack of the dentist, that's necessary to have more people working in oral health."

The ways which are welcomed to step into a unit of the public health service was also cited, exposing a sense of exclusion across their working conditions:

“But there are people who work there (public health service) and don't like we walked there... is, they think that we're dirty. But when it hurts (tooth) I'll go even. But the dentist says nothing, he has no disgust of our work."

“If I could pay (dental treatment) I wasn’t going there... I know we are talking about we're garbage. But just because I work with recyclables do I need to have my mouth spoiled?”

Although the few researches in the area of oral health to study the relationship between social exclusion and access to public health services, it is known that the there is the difficulty of access in Brazil and even more evident in groups of vulnerable individuals. To confront this reality it should be worked more with internal policies that eliminate the influence of social stereotypes in the deliberations of the daily work of health professionals [27]. And yet, broad policies that contextualize healthcare access these population groups so they can be watched in full and that the situations experienced risk can be reversed [28].

\section{Final Considerations}

Faced with the discovery of insights into the etiology and practice of care for oral health among collectors of recyclable materials, which show themselves, mostly fueled by beliefs and values collectively instituted, being linked to cognitive, economic, political, behavioral conditions, situational and social, it becomes essential to look at the value of action planning and health services.

Thus, it is suggested that the adoption of protective, educational and interceptors practice in oral health, among disadvantaged communities socially, is also developed guided by qualitative information about the problem and ways to address it, with a view to empowering individuals and communities.

\section{References}

[1] Dall’Agnol, C.M. and Fernandes, F.S. (2007) Health and Self-Care among Garbage Collectors: Work Experiences in a 
Recyclable Garbage Cooperative. Revista Latino-America de Enfermagem, 15, 729-735. http://dx.doi.org/10.1590/S0104-11692007000700003

[2] Magni, A.A.C. and Gunther, W.M.R. (2014) Cooperatives of Waste Pickers as an Alternative to Social Exclusion and Its Relationship with the Homeless Population. Saúde e Sociedade, 23, 146-156. http://dx.doi.org/10.1590/S0104-12902014000100011

[3] Ulinski, K.G.B., Nascimento, M.A., Lima, A.M.C., Benetti, A.R., Poli-Frederico, R.C., Fernandes, K.B.P., Fracasso, M.L.C. and Maciel, S.M. (2013) Factors Related to Oral Health-Related Quality of Life of Independent Brazilian Elderly. International Journal of Dentistry, 2013, 1-8. http://dx.doi.org/10.1155/2013/705047

[4] Berhane, H.Y. and Worku, A. (2014) Oral Health of Young Adolescents in Addis Ababa-A Community-Based Study. Open Journal of Preventive Medicine, 4, 640-648. http://dx.doi.org/10.4236/ojpm.2014.48073

[5] Minayo, M.C.S. and Sanches, O. (1993) Quantitative and Qualitative: Opposition or Complementarity? Cadernos de Saúde Pública, 9, 239-262. http://dx.doi.org/10.1590/S0102-311X1993000300002

[6] Merton, R., Fiske, M. and Kendal, P. (1956) The Focused Interview. Ballachulish, Glencoe.

[7] Veiga, L. and Gondim, S.M.G. (2001) The Use of Qualitative Methods in Political Science and Political Marketing. Opinião Pública, 2, 1-15.

[8] Bardin, L. (1979) Content Analysis. Lisboa, PT.

[9] Minayo, M.C.S., Hartez, Z.M.A. and Buss, P.M. (2000) Quality of Life and Health: A Necessary Debate. Ciencia \& Saúde Coletiva, 5, 7-18. http://dx.doi.org/10.1590/S1413-81232000000100002

[10] Minayo, M.C.S. (2007) The Challenge of Knowledge. Hucitec, São Paulo.

[11] Reis, S.C.G.B. and Marcelo, V.C. (2006) Oral Health in Old Age: Elderly’s Perceptions, Goiânia, 2005. Ciência \& Saúde Coletiva, 11, 191-199. http://dx.doi.org/10.1590/S1413-81232006000100028

[12] Vale, E.B., Mendes, C. and Moreira, R.S. (2013) Self-Perceived Oral Health among Adults in Northeastern Brazil. Revista de Saúde Pública, 47, 98-108. http://dx.doi.org/10.1590/S0034-8910.2013047004893

[13] Roberts, K. and Condon, L. (2014) How Do Parents Look after Children's Teeth? A Qualitative Study of Attitudes to Oral Health in the Early Years. Community Practitioner, 87, 32-35.

[14] Stahlnacke, K., Unell, L., Soderfeldt, B., Ekbäck, G. and Ordell, S. (2010) Self-Perceived Oral Health among 65 and 75 Year Olds in Two Swedish Counties. Swedish Dental Journal, 34, 107-119.

[15] Gebhardt, H., Glaser, R., Radtke, U. and Reuber, P. (2007) Geographie: Physische Geographie and Humangeographie. Spektrum Akademischer Verlag, Heidelberg.

[16] Borenstein, H., Renahy, E., Quiñonez, C. and O’Campo, P. (2013) Oral Health, Oral Pain, and Visits to the Dentist: Neighborhood Influences among a Large Diverse Urban Sample of Adults. Journal of Urban Health, 90, 1064-1078. http://dx.doi.org/10.1007/s11524-013-9802-2

[17] Costa, E.H.M., Saintrain, M.V.L. and Vieira, A.P.G.F. (2010) Self-Perception of Oral Health Condition of the Institutionalized and Non Institutionalized Elders. Ciência \& Saúde Coletiva, 15, 2925-2930. http://dx.doi.org/10.1590/S1413-81232010000600030

[18] Mason, J., Pearce, M.S., Walls, A.W.G., Parker, L. and Steele, J.G. (2006) How Do Factors at Different Stages of the Lifecourse Contribute to Oral-Health-Related Quality of Life in Middle Age for Men and Women? Journal of Dental Research, 85, 257-261. http://dx.doi.org/10.1177/154405910608500310

[19] Bircher, J. and Kuruvilla, S. (2014) Defining Health by Addressing Individual, Social, and Environmental Determinants: New Opportunities for Healthcare and Public Health. Journal of Public Health Policy, 35, 363-386. http://dx.doi.org/10.1057/jphp.2014.19

[20] Freeman, T., Jolley, G., Baum, F., Lawless, A., Javanparast, S. and Labonté, R. (2014) Community Assessment Workshops: A Group Method for Gathering Client Experiences of Health Services. Health and Social Care in the Community, 22, 47-56. http://dx.doi.org/10.1111/hsc.12060

[21] Nordenram, G., Davidson, T., Gynther, G., Helgesson, G., Hultin, M., Jemt, T., Tanaeus, S., et al. (2013) Qualitative Studies of Patients' Perceptions of Loss of Teeth, the Edentulous State and Prosthetic Rehabilitation: A Systematic Review with Meta-Synthesis. Acta Odontologica Scandinavica, 71, 937-951. http://dx.doi.org/10.3109/00016357.2012.734421

[22] Marchi, R.J., Leal, A.F., Padilha, D.M. and Brondani, M.A. (2012) Vulnerability and the Psychosocial Aspects of Tooth Loss in Old Age: A Southern Brazilian Study. Journal of Cross-Cultural Gerontology, 27, 239-258. http://dx.doi.org/10.1007/s10823-012-9170-5

[23] Lopes, M.C., Oliveira, V.M.B. and Florio, F.M. (2010) Oral Condition, Habits and Treatment Necessity of Institutionalized Elders in Araras (SP, Brazil). Ciência \& Saúde Coletiva, 15, 2949-2954. http://dx.doi.org/10.1590/S1413-81232010000600033 
[24] Bastos, J.L.D., Gigante, D.P., Peres, K.G. and Nedel, F.B. (2007) Social Determinants of Odontalgia in Epidemiological Studies: Theoretical Review and Proposed Conceptual Model. Ciência \& Saúde Coletiva, 12, 1611-1621. http://dx.doi.org/10.1590/S1413-81232007000600022

[25] Miotto, M.H.M.B., Silotti, J.C.B. and Barcellos, L.A. (2012) Dental Pain as the Motive for Absenteeism in a Sample of Workers. Ciência \& Saúde Coletiva, 17, 1357-1363. http://dx.doi.org/10.1590/S1413-81232012000500029

[26] Pandolfi, M., Barcellos, L.A. and Miotto, M.H.M.B. (2006) Users Profile and Reason Demand for Dental of Services Units Health from Vitória-ES. UFES Revista de Odontologia, 8, 44-37.

[27] Cabral, E.D., Caldas Jr., A.F. and Cabral, H.A.M. (2005) Influence of the Patient's Race on the Dentist's Decision to Extract or Retain a Decayed Tooth. Community Dentistry and Oral Epidemiology, 33, 461-466. http://dx.doi.org/10.1111/j.1600-0528.2005.00255.x

[28] Silva, D.D., Sousa, M.L.R. and Wada, R.S. (2005) Self-Perception and Oral Health Conditions in an Elderly Population. Cadernos de Saúde Pública, 21, 1251-1259. http://dx.doi.org/10.1590/S0102-311X2005000400028 
Scientific Research Publishing (SCIRP) is one of the largest Open Access journal publishers. It is currently publishing more than 200 open access, online, peer-reviewed journals covering a wide range of academic disciplines. SCIRP serves the worldwide academic communities and contributes to the progress and application of science with its publication.

Other selected journals from SCIRP are listed as below. Submit your manuscript to us via either submit@scirp.org or Online Submission Portal.
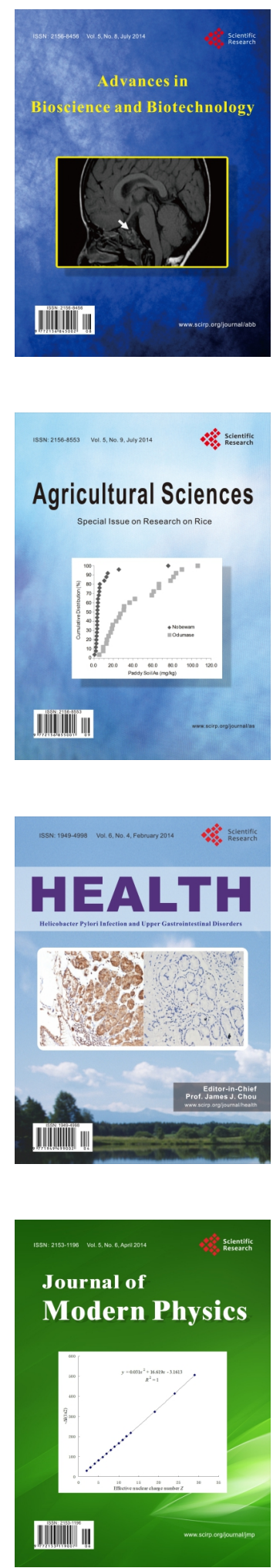
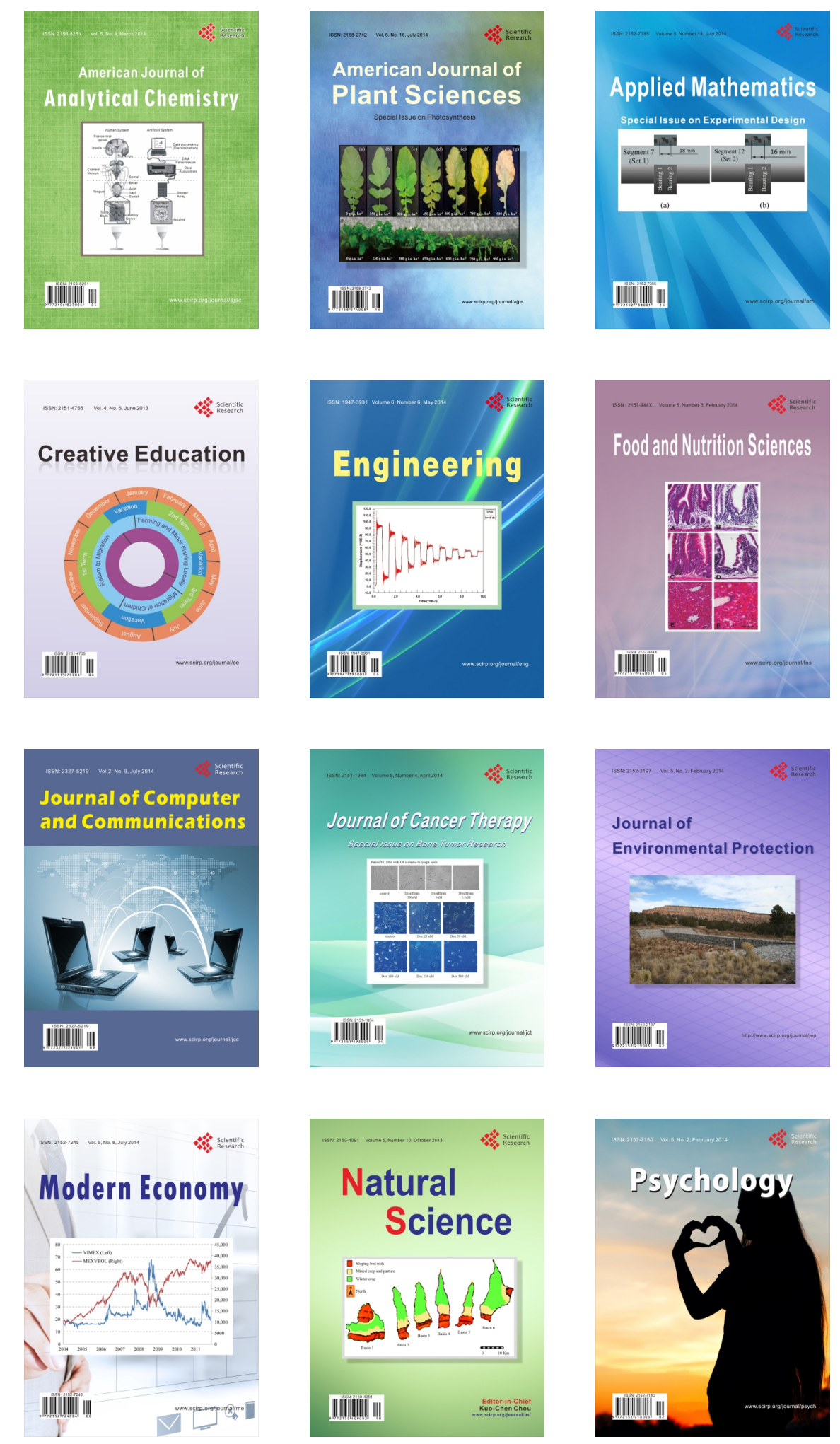